\title{
Fault detection and classification based on DWT and modern approaches for T.L compensated with FACTS
}

\author{
Noha Mahmoud Bastawy, Hossam El-din Talaat, Amr Mohamed Ibrahim \\ Electrical Power \& Machines Dept., Faculty of Engineering, Ain Shams University, Cairo, Egypt \\ Email address: \\ nohamahmoudbastawy@hotmail.co.uk (N. M. Bastawy), hossam_talaat@eng.asu.edu.eg (H. El-din Talaat), \\ amrmohamedhassan@yahoo.com (A. M. Ibrahim)
}

\section{To cite this article:}

Noha Mahmoud Bastawy, Hossam El-din Talaat, Amr Mohamed Ibrahim. Fault Detection and Classification Based on DWT and Modern Approaches for T.L Compensated with FACTS. American Journal of Electrical Power and Energy Systems. Vol. 2, No. 6, 2013, pp. 149-155. doi: 10.11648/j.epes.20130206.15

\begin{abstract}
A new approach for detecting and classifying a fault for transmission line compensated with Flexible AC Transmission System (FACTS) is presented in this paper. Unified Power Flow Controller (UPFC) is one of the most advanced FACTS devices that can simultaneously and independently control both the real and reactive power flow in a transmission line. The proposed technique consists of preprocessing module based on Discrete Wavelet Transform (DWT) in combination with Artificial Neural Network (ANN) or Gaussian Process (GP) for detecting and classifying fault events.
\end{abstract}

Keywords: Neural Network, Gaussian Process, Discrete Wavelet Transform, FACTS

\section{Introduction}

Electricity market activities and a growing demand for electricity have led to heavily stressed power systems. This requires operation of the networks closer to their stability limits. The flexible alternating current transmission system (FACTS), a new technology based on power electronics, offers an opportunity to enhance controllability, stability, and power transfer capability of ac transmission systems [1-5].

Unified Power Flow Controller (UPFC) is regarded as the most generalized version of FACTS. UPFC consists of a static synchronous series compensator (SSSC) and a static compensator (STATCOM), connected in such a way that they share a common DC capacitor. The UPFC, by means of an angularly unconstrained, series voltage injection, is able to control, concurrently or selectively, the transmission line impedance, the nodal voltage magnitude, and the active and reactive power flow through it. It may also provide independently controllable shunt reactive compensation [6-12].

Although the UPFC improves the power flow in the transmission line, its presence imposes a number of problems including distance protection. The apparent impedance seen by a distance relay is influenced greatly by the location and parameters of UPFC [13], [14]. Thus an adaptive relay setting of the distance protection is required to cope up with the problems of over reach or under reach.

\section{Fault Detection and Classification Scheme}

"Fig. 1" shows the proposed protection scheme. It consists of two stages, Pre-processing stage based on DWT and fault classification stage based on ANN or GP. The DWT considerably simplifies the input signal of the ANN and GP; it reduces the volume of input data of ANN and GP without loss of information. This dramatically reduces the training stage in and increase the overall performance of the digital relay.

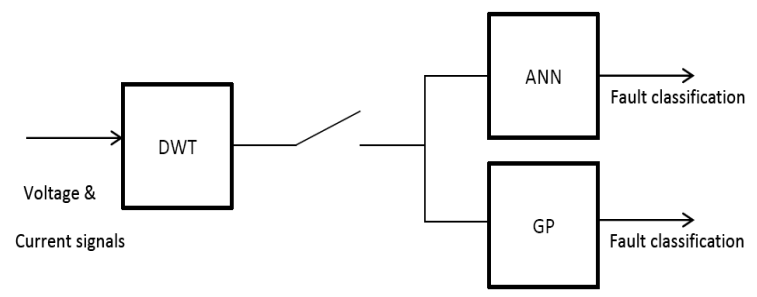

Figure 1. Fault detection and classification scheme

The proposed topology of the protection scheme is composed of two levels as shown in "Fig. 2". Level-1 is used to detect the fault, while level-2 is used to identify faulted phase(s). The output of level-1 activates level-2 if there is a fault. Therefore, the proposed topology 
determines both the fault type and the faulted phase(s) selection.

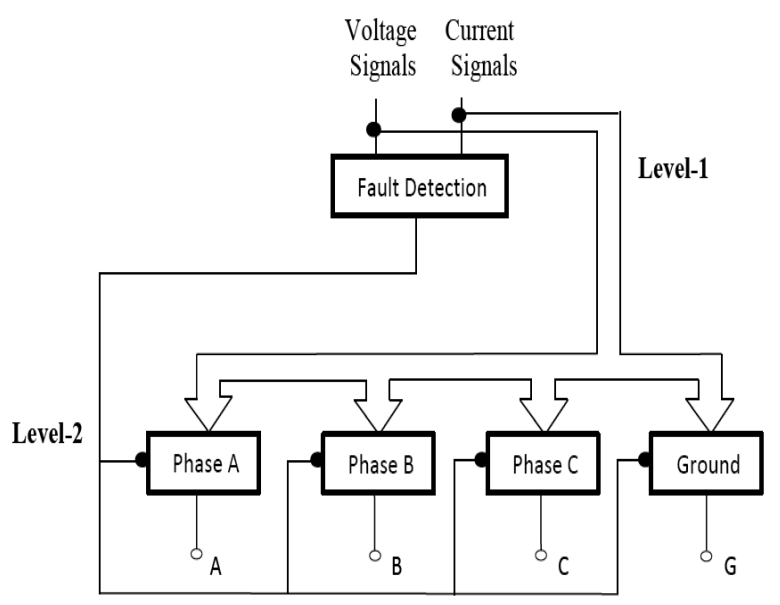

Figure 2. Proposed protection scheme

\section{Discrete Wavelet Transform}

Wavelet analysis is a relatively new signal processing tool and is applied recently by many researchers in power systems due to its strong capability of time and frequency domain analysis. The two areas with most applications are power quality analysis and power system protection [15]. The wavelet transform is the versatile tool with very rich mathematical content and great potential for applications. The wavelet transform decomposes transients into a series of wavelet components i.e. approximation and detail components. The resulting decomposed signals can then be analyzed in both time and frequency domains. Hence, the wavelet transform is feasible and practical for analyzing power system transients [16].

Wavelet transforms are fast and efficient means of analyzing transient voltage and current signals. The wavelet transform not only decomposes a signal into frequency bands, but also, unlike the Fourier transform, provides a non-uniform division of the frequency domain (i.e., the wavelet transform uses short windows at high frequencies and long windows for low frequency components). Wavelet analysis deals with expansion of functions in terms of a set of basic functions (wavelets) which are generated from a mother wavelet by operations of dilatations and translation [17-18]. The discrete wavelet transform is defined by the following equation:

$$
D W T(m, n)=\frac{1}{\sqrt{a_{0}{ }^{m}}} \sum_{k} x(k) g\left(a_{0}-m n-b_{0} k\right)
$$

Where $g(k)$ is the mother wavelet, $x(k)$ is the signal input and $\mathrm{a}, \mathrm{b}$ are the scaling and translation parameters. Discrete wavelet transform is implemented by using high-pass filter and low-pass filter respectively, which defined by the following equations:

$$
y_{\text {high }}[k]=\Sigma_{n} x[n], g[2 k-n]
$$

$$
y_{\text {ow }}[n]=\sum_{h} x[n], h[2 k-n]
$$

Where $\mathrm{y}_{\text {high }}(\mathrm{k})$ is the output from the high-pass filter called Detail and $\mathrm{y}_{\text {low }}(\mathrm{k})$ is the output from the low-pass filter called Approximation, also the output of the low-pass filter down-sampling by a factor of 2 which effectively scales the wavelet by a factor of 2 for next stage. This decomposition has halved the time resolution since only half the number of samples now characterizes the entire signal. However, this operation doubles the frequency resolution, since the frequency band of the signal now spans only half the previous frequency band. The block diagram of filter analysis is shown in "Fig. 3"

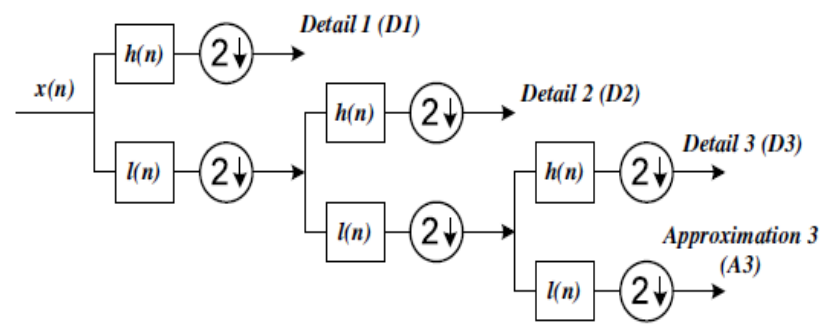

Figure 3. Wavelet multi-resolution analysis

\section{Artificial Neural Network}

Artificial Neural Networks (ANN) are simplified to imitate central nervous system been motivated by the computing performed by human brain. ANN is defined in and as a data processing system consisting of a large number of simple highly interconnected processing elements (artificial neuron) in architecture inspired by the structure of cerebral cortex of the brain [19], [20].

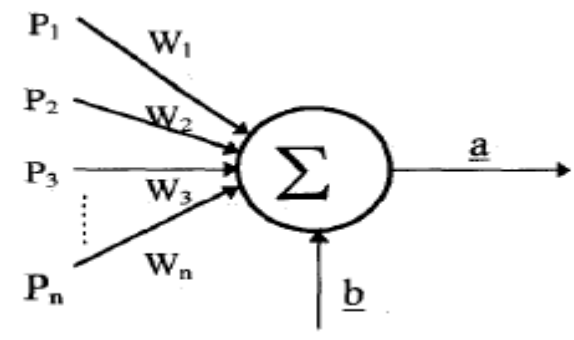

Figure 4. Perceptron representation

Once trained, a network response can be, to a degree, insensitive to minor variations in its input. This ability to see through noise and distortion to the pattern that lies within is vital to pattern recognition a real world environment [21], [22]. The neuron is the nervous cell and is represented in the ANN universe as a perceptron. "Fig. 4" shows a simple model of a neuron characterized by a number of inputs $\mathrm{P}$, $\mathrm{P} 2, \ldots, \mathrm{PN}$, than weights WI, W2, ....Wn, the bias adjust $\mathrm{b}$ and an output a. The neuron uses the input, as well as the information on its current activation state to determine the output a, given as in (4).

$$
a=\sum_{k=1}^{n} W_{k} P_{k}+b
$$




\subsection{Feed Forward Neural Network}

Feed-forward neural networks can be classified in a single layer or multilayer feed-forward neural networks. Multilayer FNN architecture comprises of input-layer(X); hidden-layer (V); and output-layer (Y); as shown in "Fig. 5" [19], [23].

The algorithm gives a prescription for changing the weights in any feed forward network to learn a training set of input-output pairs. The use of the bias adjust in the ANNs is optional, but the results may be enhanced by it. A multilayer network with one hidden layer is shown in "Fig. 5". This network consists of a set of $\mathrm{N}$ input units $(\mathrm{Xi}, \mathrm{i}=$ $1 \ldots \mathrm{N}$ ), a set of $\mathrm{p}$ output units (Yp, $\mathrm{p}=1 \ldots \mathrm{P}$ ) and a set of $\mathrm{J}$ hidden units $(\mathrm{Vj}, \mathrm{j}=1 \ldots \mathrm{J})$. Thus, the hidden unit $\mathrm{Vj}$ receives a net input and produces the output.

$$
\mathrm{V}]=F\left\{\sum_{\pi=1}^{n} W_{j k} X_{\hbar}\right\}
$$

Where $\mathrm{j}=1 \ldots \mathrm{J}$

The final output is then produced:

$$
\mathrm{Yp}=F\left\{\sum_{\mathrm{m}=1}^{j} w_{\mathrm{m} m} v_{\mathrm{m} m}\right\}
$$

Where $p=1 \ldots P$

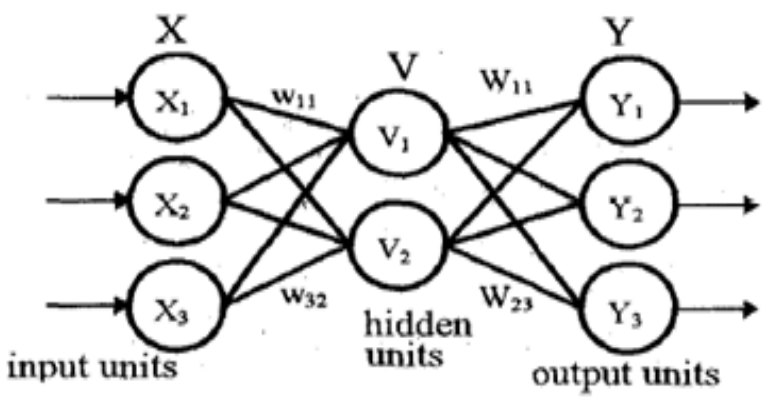

Figure 5. Multilayer Feed-forward neural network architecture

\section{Gaussian Process}

Gaussian process is a supervised learning technique that has been used for regression and classification [24]. The GP models are probabilistic, non-parametric models based on the principles of Bayesian probability [25]. It governs the properties of functions and is fully specified by a mean and a covariance functions. It is based on assigning a prior in the form of a multivariate Gaussian density that imposes a smoothness constraint on the underlying function. For the classification problem this underlying function is the posterior probability [26].

Given a training set $\mathrm{S}$ of $\mathrm{n}$ observations, $\mathrm{S}=\{(\mathrm{xi}, \mathrm{yi}) \mid \mathrm{i}=$ $1 \ldots \mathrm{n}\}$ where $\mathrm{xi}$ denotes an input vector of dimension $\mathrm{D}$ and yi denotes the target class of the corresponding input sample i. X refers to the matrix of all the training samples, $y$ denotes the vector of the class labels for all the training samples and $f$ represents the vector of the prior latent functions for all the training samples. One would like to predict the class membership probability to a test sample $\mathrm{x}^{*}$. This is achieved by obtaining the distribution of the latent function of the test sample $\mathrm{f}^{*}$ given the class memberships of the training samples. Since the underlying function corresponds to the posterior probability of class 1 , the unrestricted latent function is passed through a squashing function in order to map its value into the unit interval.

The Gaussian process is specified by an a priori multivariate distribution for the latent functions of the training and testing samples. This distribution has a covariance function that ensures that the latent functions of near-by samples are closely correlated. On the other hand, their covariance decreases with increasing the distant between their data samples; this is controlled by hyper-parameters that need to be estimated. During the training phase, the mean and the covariance of the latent function are calculated for each training sample using the algorithms in [26]. The probability that the test sample $\mathrm{x}^{*}$ belongs to class 1 is calculated as:

$$
P(y *=1 \mid X, y, x *)=\int_{-w}^{\infty} p(y *=1 \mid f *) p(f * \mid X, y, x *) d f *
$$

$\mathrm{P}\left(\mathrm{y}^{*}=1 \mid \mathrm{f}^{*}\right)$ is evaluated using sigmoid activation function:

$$
P(y *=1 \mid f i)=\sigma(y * f i)
$$

Substituting in (7), we get

$$
P(y *=1 \mid X, y, x *)=\int_{-s}^{* \pi} \sigma(y * f *) p(f * \mid X, y, x *) d f *
$$

Where

$$
P(f * \mid X, y, x *]=\int_{-x}^{z} p[f * \mid f, X, x *)(f \mid X, y) d f
$$

\section{Simulations and Results}

The proposed classification scheme is implemented on MATLAB software. It is trained and tested using measurements of three-phase voltage and current samples obtained from the PSCAD/EMTDC. "Fig. 6" shows the 220 $\mathrm{kV}, 50 \mathrm{~Hz}$ simulated system one-line diagram. "Fig. 7" shows 3 ph voltages and currents waveforms for single phase to ground fault at $50 \%$ of first line section at fault resistance $10 \mathrm{ohm}$ and fault inception angle 45 .

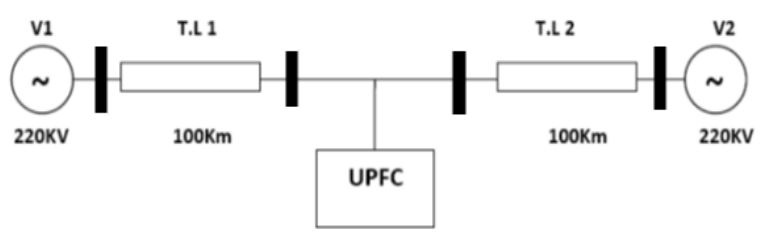

Figure 6. Transmission system with UPFC

The samples are analysed using DWT, the mother wavelet considered is Daubechies (db)4. The behaviour of the DWT for actual fault current and voltage waveforms is illustrated in "Fig. 8" for single phase to ground fault at $50 \%$ of first 
line length at fault resistance $10 \mathrm{ohm}$ and fault inception angle 45 .

All possible fault types are simulated at fault resistance 0 , $10,20 \mathrm{ohm}$ and fault inception angle $0,45,90$. Fault locations at $10 \%, 20 \%, 40 \%, 50 \%, 70 \%, 80 \%$, and $100 \%$ from the length of each line are taken for the training process of ANN \& GP. The test will begin with fault occurrence simulation at distance $30 \%, 60$ and $90 \%$ from length of each line section.
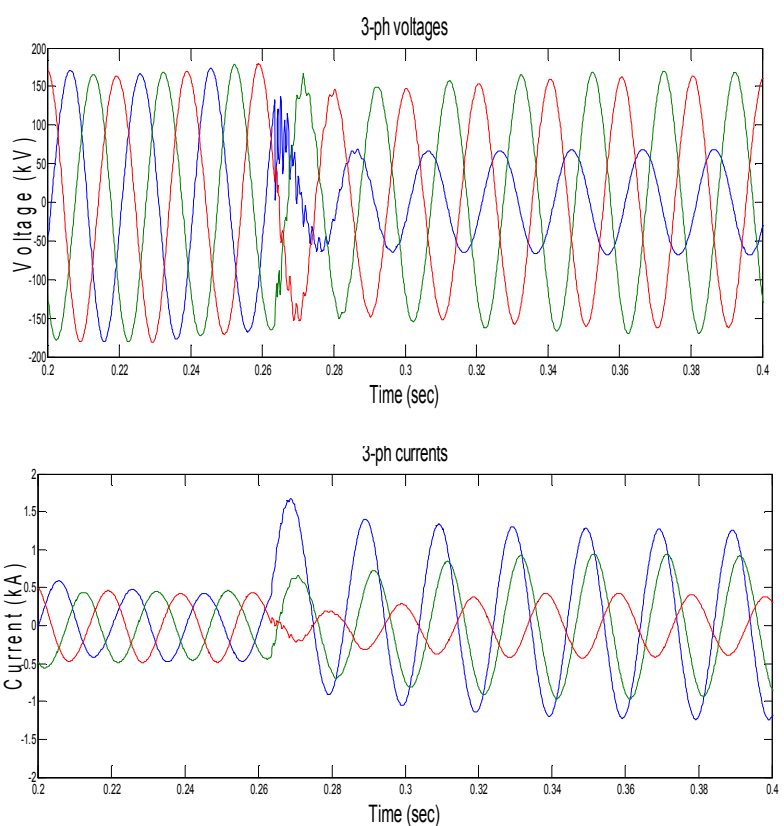

Figure 7. $3 p h$ voltages and currents waveforms for $1 p h$ to ground fault at $50 \%$ of first line section
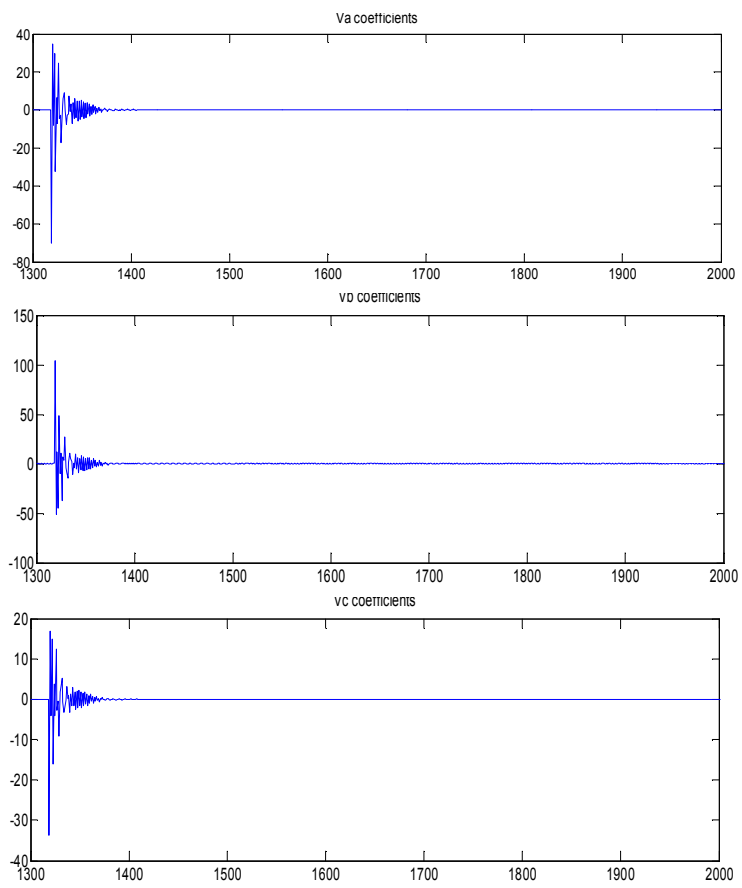
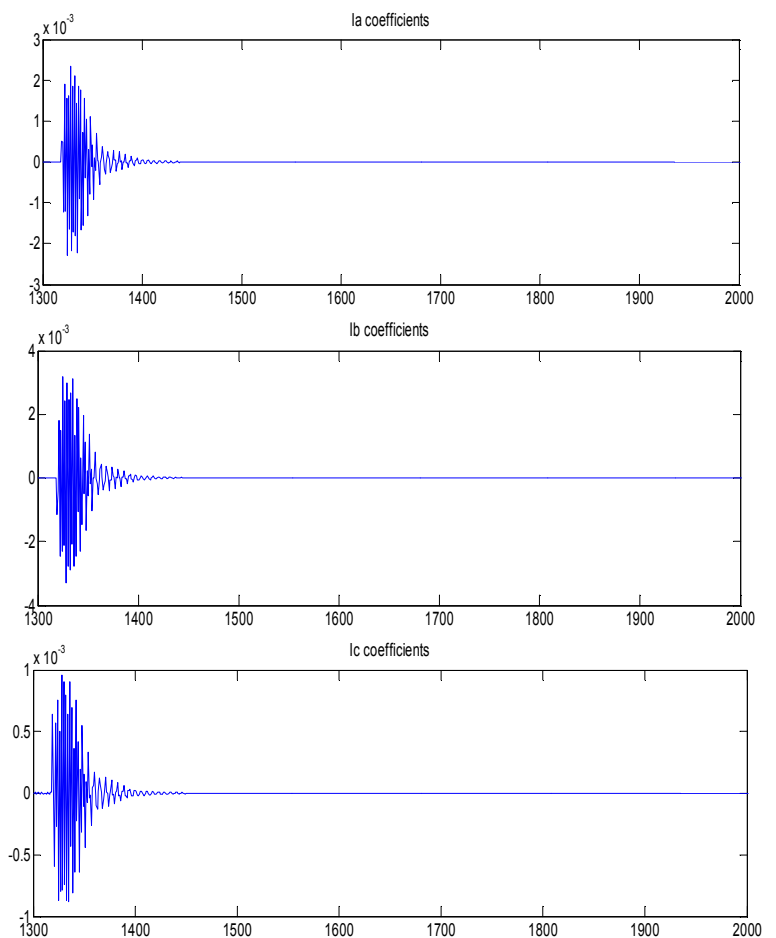

Figure 8. Detailed coefficients of $3 p h$ voltages and currents at time of fault

Table 1. Estimated output of ANN for detecting fault (Level-1)

\begin{tabular}{ccccc}
\hline Fault Type & \multicolumn{2}{c}{ Fault Location } & Desired Value & Actual Value \\
\hline A-G & $30 \%$ & $1^{\text {st }}$ line section & 1 & 1 \\
A-G & $60 \%$ & $1^{\text {st }}$ line section & 1 & 0.99 \\
A-G & $90 \%$ & $1^{\text {st }}$ line section & 1 & 1 \\
A-G & $30 \%$ & $2^{\text {nd }}$ line section & 1 & 1 \\
A-G & $60 \%$ & $2^{\text {nd }}$ line section & 1 & 0.99 \\
A-G & $90 \%$ & $2^{\text {nd }}$ line section & 1 & 1 \\
A-B & $30 \%$ & $1^{\text {st }}$ line section & 1 & 1 \\
A-B & $60 \%$ & $1^{\text {st }}$ line section & 1 & 1 \\
A-B & $90 \%$ & $1^{\text {st }}$ line section & 1 & 1 \\
A-B & $30 \%$ & $2^{\text {nd }}$ line section & 1 & 0.98 \\
A-B & $60 \%$ & $2^{\text {nd }}$ line section & 1 & 0.95 \\
A-B & $90 \%$ & $2^{\text {nd }}$ line section & 1 & 0.96 \\
AB-G & $30 \%$ & $1^{\text {st }}$ line section & 1 & 1 \\
AB-G & $60 \%$ & $1^{\text {st }}$ line section & 1 & 1 \\
AB-G & $90 \%$ & $1^{\text {st }}$ line section & 1 & 1 \\
AB-G & $30 \%$ & $2^{\text {nd }}$ line section & 1 & 0.99 \\
AB-G & $60 \%$ & $2^{\text {nd }}$ line section & 1 & 0.98 \\
AB-G & $90 \%$ & $2^{\text {nd }}$ line section & 1 & 1 \\
ABC-G & $30 \%$ & $1^{\text {st }}$ line section & 1 & 1 \\
ABC-G & $60 \%$ & $1^{\text {st }}$ line section & 1 & 0.99 \\
ABC-G & $90 \%$ & $1^{\text {st }}$ line section & 1 & 1 \\
ABC-G & $30 \%$ & $2^{\text {nd }}$ line section & 1 & 1 \\
ABC-G & $60 \%$ & $2^{\text {nd }}$ line section & 1 & 1 \\
ABC-G & $90 \%$ & $2^{\text {nd }}$ line section & 1 & 1 \\
\hline & & & & 1 \\
\hline
\end{tabular}


Table 2. Estimated output of GP for detecting fault (Level-1)

\begin{tabular}{ccccc}
\hline Fault Type & \multicolumn{2}{c}{ Fault Location } & Desired Value & Actual Value \\
\hline A-G & $30 \%$ & $1^{\text {st }}$ line section & 1 & 1 \\
A-G & $60 \%$ & $1^{\text {st }}$ line section & 1 & 1 \\
A-G & $90 \%$ & $1^{\text {st }}$ line section & 1 & 1 \\
A-G & $30 \%$ & $2^{\text {nd }}$ line section & 1 & 1 \\
A-G & $60 \%$ & $2^{\text {nd }}$ line section & 1 & 1 \\
A-G & $90 \%$ & $2^{\text {nd }}$ line section & 1 & 1 \\
A-B & $30 \%$ & $1^{\text {st }}$ line section & 1 & 1 \\
A-B & $60 \%$ & $1^{\text {st }}$ line section & 1 & 1 \\
A-B & $90 \%$ & $1^{\text {st }}$ line section & 1 & 1 \\
A-B & $30 \%$ & $2^{\text {nd }}$ line section & 1 & 1 \\
A-B & $60 \%$ & $2^{\text {nd }}$ line section & 1 & 1 \\
A-B & $90 \%$ & $2^{\text {nd }}$ line section & 1 & 1 \\
\hline
\end{tabular}

\begin{tabular}{ccccc}
\hline Fault Type & \multicolumn{2}{c}{ Fault Location } & Desired Value & Actual Value \\
\hline AB-G & $30 \%$ & $1^{\text {st }}$ line section & 1 & 1 \\
AB-G & $60 \%$ & $1^{\text {st }}$ line section & 1 & 1 \\
AB-G & $90 \%$ & $1^{\text {st }}$ line section & 1 & 1 \\
AB-G & $30 \%$ & $2^{\text {nd }}$ line section & 1 & 1 \\
AB-G & $60 \%$ & $2^{\text {nd }}$ line section & 1 & 1 \\
AB-G & $90 \%$ & $2^{\text {nd }}$ line section & 1 & 1 \\
ABC-G & $30 \%$ & $1^{\text {st }}$ line section & 1 & 1 \\
ABC-G & $60 \%$ & $1^{\text {st }}$ line section & 1 & 1 \\
ABC-G & $90 \%$ & $1^{\text {st }}$ line section & 1 & 1 \\
ABC-G & $30 \%$ & $2^{\text {nd }}$ line section & 1 & 1 \\
ABC-G & $60 \%$ & $2^{\text {nd }}$ line section & 1 & 1 \\
ABC-G & $90 \%$ & $2^{\text {nd }}$ line section & 1 & 1 \\
\hline
\end{tabular}

Table 3. Estimated output of ANN for classifying fault (Level-2)

\begin{tabular}{|c|c|c|c|c|c|c|c|c|}
\hline \multirow{2}{*}{ • } & \multicolumn{2}{|c|}{ Phase A } & \multicolumn{2}{|c|}{ Phase B } & \multicolumn{2}{|c|}{ Phase C } & \multicolumn{2}{|c|}{ Ground } \\
\hline & Desired & Actual & Desired & Actual & Desired & Actual & Desired & Actual \\
\hline A-G at $30 \% 1^{\text {st }}$ line & 1 & 1 & 0 & 0 & 0 & 0 & 1 & 1 \\
\hline A-G at $60 \% 1^{\text {st }}$ line & 1 & 1 & 0 & 0 & 0 & 0 & 1 & 1 \\
\hline A-G at $90 \% 1^{\text {st }}$ line & 1 & 1 & 0 & 0 & 0 & 0.03 & 1 & 0.99 \\
\hline A-G at $30 \% 2^{\text {nd }}$ line & 1 & 0.89 & 0 & 0 & 0 & 0 & 1 & 1 \\
\hline A-G at $60 \% 2^{\text {nd }}$ line & 1 & 1 & 0 & 0 & 0 & 0 & 1 & 1 \\
\hline A-G at $90 \% 2^{\text {nd }}$ line & 1 & 1 & 0 & 0 & 0 & 0 & 1 & 1 \\
\hline A-B at $30 \% 1^{\text {st }}$ line & 1 & 0.99 & 1 & 0.99 & 0 & 0.001 & 0 & 0 \\
\hline A-B at $60 \% 1^{\text {st }}$ line & 1 & 1 & 1 & 1 & 0 & 0 & 0 & 0 \\
\hline A-B at $90 \% 1^{\text {st }}$ line & 1 & 1 & 1 & 1 & 0 & 0 & 0 & 0 \\
\hline A-B at $30 \% 2^{\text {nd }}$ line & 1 & 0.97 & 1 & 1 & 0 & 0.16 & 0 & 1 \\
\hline A-B at $60 \% 2^{\text {nd }}$ line & 1 & 0.96 & 1 & 1 & 0 & 0 & 0 & 0 \\
\hline A-B at $90 \% 2^{\text {nd }}$ line & 1 & 1 & 1 & 1 & 0 & 0 & 0 & 0 \\
\hline AB-G at $30 \% 1^{\text {st }}$ line & 1 & 1 & 1 & 1 & 0 & 0.002 & 1 & 1 \\
\hline AB-G at $60 \% 1^{\text {st }}$ line & 1 & 1 & 1 & 0.99 & 0 & 0 & 1 & 0.99 \\
\hline AB-G at $90 \% 1^{\text {st }}$ line & 1 & 1 & 1 & 1 & 0 & 0 & 1 & 0.99 \\
\hline AB-G at $30 \% 2^{\text {nd }}$ line & 1 & 1 & 1 & 1 & 0 & 0.09 & 1 & 1 \\
\hline$A B-G$ at $60 \% 2^{\text {nd }}$ line & 1 & 1 & 1 & 1 & 0 & 0 & 1 & 1 \\
\hline AB-G at $90 \% 2^{\text {nd }}$ line & 1 & 0.97 & 1 & 1 & 0 & 0.01 & 1 & 0.92 \\
\hline ABC-G at $30 \% 1^{\text {st }}$ line & 1 & 1 & 1 & 1 & 1 & 1 & 1 & 0.99 \\
\hline ABC-G at $60 \% 1^{\text {st }}$ line & 1 & 1 & 1 & 0.99 & 1 & 1 & 1 & 0 \\
\hline ABC-G at $90 \% 1^{\text {st }}$ line & 1 & 0.98 & 1 & 0.99 & 1 & 1 & 1 & 0.88 \\
\hline ABC-G at $30 \% 2^{\text {nd }}$ line & 1 & 1 & 1 & 1 & 1 & 1 & 1 & 1 \\
\hline ABC-G at $60 \% 2^{\text {nd }}$ line & 1 & 1 & 1 & 1 & 1 & 1 & 1 & 1 \\
\hline$A B C-G$ at $90 \% 2^{\text {nd }}$ line & 1 & 0.96 & 1 & 1 & 1 & 0 & 1 & 1 \\
\hline
\end{tabular}


Table 4. Estimated output of GP for classifying fault (Level-2)

\begin{tabular}{|c|c|c|c|c|c|c|c|c|}
\hline \multirow{2}{*}{ Fault type \& location } & \multicolumn{2}{|c|}{ Phase A } & \multicolumn{2}{|c|}{ Phase B } & \multicolumn{2}{|c|}{ Phase C } & \multicolumn{2}{|c|}{ Ground } \\
\hline & Desired & Actual & Desired & Actual & Desired & Actual & Desired & Actual \\
\hline A-G at $30 \% 1^{\text {st }}$ line & 1 & 1 & -1 & -1 & -1 & -1 & 1 & 1 \\
\hline A-G at $60 \% 1^{\text {st }}$ line & 1 & 1 & -1 & -1 & -1 & -1 & 1 & 1 \\
\hline A-G at $90 \% 1^{\text {st }}$ line & 1 & 1 & -1 & -1 & -1 & -1 & 1 & 1 \\
\hline A-G at $30 \% 2^{\text {nd }}$ line & 1 & 1 & -1 & 1 & -1 & 1 & 1 & 1 \\
\hline A-G at $60 \% 2^{\text {nd }}$ line & 1 & 1 & -1 & -1 & -1 & 1 & 1 & 1 \\
\hline A-G at $90 \% 2^{\text {nd }}$ line & 1 & 1 & -1 & -1 & -1 & -1 & 1 & 1 \\
\hline A-B at $30 \% 1^{\text {st }}$ line & 1 & 1 & 1 & 1 & -1 & -1 & -1 & -1 \\
\hline A-B at $60 \% 1^{\text {st }}$ line & 1 & 1 & 1 & 1 & -1 & -1 & -1 & -1 \\
\hline A-B at $90 \% 1^{\text {st }}$ line & 1 & 1 & 1 & 1 & -1 & -1 & -1 & -1 \\
\hline A-B at $30 \% 2^{\text {nd }}$ line & 1 & 1 & 1 & 1 & -1 & 1 & -1 & -1 \\
\hline A-B at $60 \% 2^{\text {nd }}$ line & 1 & 1 & 1 & 1 & -1 & -1 & -1 & -1 \\
\hline A-B at $90 \% 2^{\text {nd }}$ line & 1 & 1 & 1 & 1 & -1 & -1 & -1 & -1 \\
\hline $\mathrm{AB}-\mathrm{G}$ at $30 \% 1^{\text {st }}$ line & 1 & 1 & 1 & 1 & -1 & -1 & 1 & 1 \\
\hline AB-G at $60 \% 1^{\text {st }}$ line & 1 & 1 & 1 & 1 & -1 & -1 & 1 & 1 \\
\hline AB-G at $90 \% 1^{\text {st }}$ line & 1 & 1 & 1 & 1 & -1 & -1 & 1 & 1 \\
\hline$A B-G$ at $30 \% 2^{\text {nd }}$ line & 1 & 1 & 1 & 1 & -1 & 1 & 1 & 1 \\
\hline$A B-G$ at $60 \% 2^{\text {nd }}$ line & 1 & 1 & 1 & 1 & -1 & 1 & 1 & 1 \\
\hline AB-G at $90 \% 2^{\text {nd }}$ line & 1 & 1 & 1 & 1 & -1 & -1 & 1 & -1 \\
\hline ABC-G at $30 \% 1^{\text {st }}$ line & 1 & 1 & 1 & 1 & 1 & 1 & 1 & 1 \\
\hline ABC-G at $60 \% 1^{\text {st }}$ line & 1 & 1 & 1 & 1 & 1 & 1 & 1 & 1 \\
\hline ABC-G at $90 \% 1^{\text {st }}$ line & 1 & 1 & 1 & 1 & 1 & 1 & 1 & 1 \\
\hline$A B C-G$ at $30 \% 2^{\text {nd }}$ line & 1 & 1 & 1 & 1 & 1 & -1 & 1 & -1 \\
\hline $\mathrm{ABC}-\mathrm{G}$ at $60 \% 2^{\text {nd }}$ line & 1 & 1 & 1 & 1 & 1 & 1 & 1 & 1 \\
\hline$A B C-G$ at $90 \% 2^{\text {nd }}$ line & 1 & 1 & 1 & 1 & 1 & 1 & 1 & -1 \\
\hline
\end{tabular}

Table 1 and Table 2 show some parts of calculations of test results for artificial neural network and Gaussian process at fault resistance $10 \mathrm{ohm}$ and fault inception angle 45 for detecting faults (Level-1). The output of ANN for level-1 is either 0 or 1 indicating that there is a fault or not and for GP is either 1 indicating a fault or -1 indicating no fault condition.

Table 3 and Table 4 show some parts of calculations of test results for ANN and GP at fault resistance $10 \mathrm{ohm}$ and fault inception angle 45 for classifying faults (Level-2).

The neural network achieves higher test accuracy than the Gaussian process method. The test accuracy in detection level reached $100 \%$ for ANN \& 100\% for GP. The overall test accuracy in classification level reached $96.2 \%$ for ANN \& $90 \%$ for GP.

\section{Conclusion}

The use of an ANN and GP as a pattern classifier to improve the performance of distance relay in transmission system compensated with FACTS is discussed in this paper. The neural network achieves higher test accuracy than the Gaussian process method. The proposed approach is designed to detect the faults, to classify the fault type, and to identify the faulted phase. The wavelet transform provides an efficient way to extract signal components at different frequency bands.

\section{References}

[1] John J. Paserba, "How FACTS Controllers Benefit AC Transmission Systems", Transmission and Distribution Conference and Exposition, 2003 IEEE PES, Vol. 3, pp. 949-956, September 2003.

[2] John Wiley, "FACTS Modeling and Simulation in Power Networks", 2004.

[3] T. Manokaran, V.Karpagam, "Performance of Distance Relay Estimation in Transmission Line with UPFC", International Journal of Computer and Electrical Engineering, Vol. 2, No. 1, pp. 158-161, February 2010.

[4] Pavlos S. Georgilakis, Peter G. Vernados, "Flexible AC Transmission System Controllers", Materials Science Forum Vol. 670, pp 399-406, 2011.

[5] Lijun Cai, "Robust Coordinated Control of FACTS Devices in Large Power Systems", published by Logos Verlag Berlin 2004. 
[6] Tomasz Okon and Kazimierz Wilkosz, "Influence of UPFC Device on Power System State Estimation", PowerTech IEEE, pp. 1-8, June 2011.

[7] Tomasz Okon, Kazimierz Wilkosz," Consideration of Different Operation Modes of UPFC in Power System State Estimation", Environment and Electrical Engineering (EEEIC) 10th International Conference, pp. 1-4, May 2011.

[8] Bo Hu, Kaigui Xie, Rajesh Karki, "Reliability Evaluation of Bulk Power Systems Incorporating UPFC”, IEEE 2010.

[9] C. D. Schauder, L. Gyugyi, M. R. Lund, D. M. Hamai, T. R. Rietman, D. R. Torgerson, and A. Edris, "Operation of The Unified Power Flow Controller (UPFC) Under Practical Constrains", IEEE Transactions on Power Delivery, Vol. 13, No. 2, pp. 630-639, April 1998.

[10] Nampetch P., S.N. Singh, and Surapong C., "Modeling of UPFC and Its Parameters Selection", Power Electronics and Drive Systems 4th IEEE International Conference, Vol. 1, pp. 77-83, October 2011.

[11] Ali Ajami, S.H. Hosseini, and G.B. Gharehpetian, "Modelling and Controlling of UPFC for Power System Transient Studies", ECTI Transactions on Electrical Eng., Electronics, and Communications, Vol. 5, No. 2, pp. 29-35, August 2007.

[12] Mehrdad Ahmadi Kamarposhti, Mostafa Alinezhad, Hamid Lesani, Nemat Talebi, "Comparison of SVC, STATCOM, TCSC, and UPFC Controllers for Static Voltage Stability Evaluated by Continuation Power Flow Method", IEEE Electrical Power \& Energy Conference, pp. 1-8, October 2008 .

[13] P. K. Dash, A. K. Pradhan, G. Panda, A. C. Liew, "Digital Protection of Power Transmission Lines in The Presence of Series Connected FACTS Devices", IEEE, Vol. 3, pp. 1967-1972, January 2000.

[14] P.K. Dash, A.K. Pradhan, G. Panda, "Distance protection in the presence of unified power flow controller", Electric Power Systems Research 54, pp. 189-198, 2000.

[15] N.Zhang, M.Kezunovic, "Transmission Line Boundary Protection Using Wavelet Transform and Neural Network", IEEE Transactions on Power Delivery, Vol. 22, Issue 2, pp. 859-869, April 2007.

[16] Sriya Chakraborty, Shalini Singh, Anu Bhalla, Pallavi Saxena, Ramesh Padarla, "Wavelet Transform Based Fault Detection and Classification in Transmission Line", International Journal of Research in Engineering \& Applied Sciences, ISSN: 2249-3905, Vol. 2, Issue 5, May 2012.
[17] Abdulhamid A. Abohagar, M.W.Mustafa, "Back Propagation Neural Network Aided Wavelet Transform for High Impedance Fault Detection and Faulty Phase Selection", IEEE International Conference on Power and Energy (PECon), pp. 790-795, December 2012.

[18] Francisco Martín, José A. Aguado, "Wavelet-Based ANN Approach for Transmission Line Protection", IEEE Transactions on Power Delivery, Vol. 18, No. 4, pp. 1572-1574, October 2003.

[19] Anant Oonsivilai, Sanom Saichoomdee, "Appliance of Recurrent Neural Network toward Distance Transmission Lines Protection”, IEEE, pp. 1-4, January 2009.

[20] Janison R. de Carvalho, Denis V. Coury, Carlos A. Duque, David C. Jorge, "Development of Detection and Classification Stages for a New Distance Protection Approach Based on Cumulants and Neural Networks", Power and Energy Society General Meeting IEEE, pp. 1-7, July 2011.

[21] A.P.Vaidy, Prasad A. Venikar, "ANN Based Distance Protection of Long Transmission Lines by Considering the Effect of Fault Resistance", IEEE - International Conference On Advances In Engineering, Science And Management, pp. 590-594, March 2012.

[22] D.V Coury, D.C Jorge, “Artificial Neural Network Approach to Distance Protection of Transmission Lines", IEEE Transactions on Power Delivery, Vol. 13, No. 1, pp. 102-108, January 1998.

[23] E.A. Feilat and K. AI-Tallaq, "A New Approach For Distance Protection Using Artificial Neural Network", Universities Power Engineering Conference UPEC, Vol. 1, pp. 473-477, September 2004.

[24] Hannes Nickisch, Carl Edward Rasmussen, “Approximations for binary Gaussian process classification", Journal of Machine Learning Research 9, pp. 2035-2078, 2008.

[25] Pavle Boškoski, Matej Gašperin, Dejan Petelin, "Bearing fault prognostics based on signal complexity and Gaussian process models", IEEE conference, 2012.

[26] C. E. Rasmussen, C. K. I. Williams, "Gaussian Processes for Machine Learning”, MIT Press, Cambridge 2006. 